\title{
THE EFFECTS OF TANNIC ACID ON THE EFFECTIVENESS OF EGG FERTILIZATION AND REMOVING CARP EGG ADHESIVENESS
}

Gražina ŽIBIENĖ, Hydraulic Engineering Institute, Faculty of Water and Land Management, Aleksandras Stulginskis University. Address: Universiteto 10, Akademija 53361, Kaunas district, Lithuania, grazina.zibiene@asu.lt.

Alvydas ŽIBAS, Hydraulic Engineering Institute, Faculty of Water and Land Management, Aleksandras Stulginskis University, Address: Studentų 11, Akademija 53361, Kaunas district, Lithuania, alvydas.zibas@ lzuu.lt.

Laima ŠVIRINIENÉ, Šilavotas Subdivision under the Division of Internal Water and Aquaculture of Fisheries Service under the Ministry of Agriculture of the Republic of Lithuania, Mikalinė vill., Šilavotas subdistr., Prienai distr., Lithuania, laima.sviriniene@ zuv.lt.

Egg adhesiveness is one of the major problems in carp artificial breeding. The appropriate elimination of egg adhesiveness impacts the effectiveness of the breeding. This article discusses two used methods of carp egg adhesiveness removal: tannic acid+water and milk+water+salt solutions. Milk, water and salt solution was based on the following proportions: 1 litre of milk +7 litres of water $+50 \mathrm{~g}$ of $\mathrm{NaCl}$. Adhesiveness is removed from fertilized eggs in bowls by mixing them with geese feathers for no shorter than 60 minutes. The tannic acid solution was prepared by mixing 7 grams of tannic acid powder with 5 litres of water. 1 litre of solution is immediately poured into a bowl with fertilized eggs. Adhesiveness is removed from fertilized eggs in bowls by intensively mixing them for 10 minutes. After fertilization and removal of adhesiveness, the eggs were transferred into Weiss jars. The results showed that during the process of incubation, 3.7 million eggs were fertilized; out of them 1.6 million were rid of adhesiveness by milk solution, 2.1 - by tannic solution. It is plausible that unfavourable environmental conditions influenced the low egg vitality. 750000 (47\%) carp larvae hatched from milk solution treated eggs, while 800000 (38\%) of larvae hatched from the eggs treated with tannic solution.

Keywords: fertilization, adhesiveness, tannic acid, common carp

\section{INTRODUCTION}

Carp is one of the most frequently grown fish in pond fishery in Lithuania. For a long time carp reproduction was performed in natural hatching ponds. The effectiveness of hatchering was measured by counting the number of hatched larvae. Naturally, the effectiveness of hatchering depended on climate conditions. When carp spawn naturally, released eggs become sticky in contact with water. In natural conditions, the eggs adhere to water plants, disperse over a large area and do not stick to one another (Riehl R. and Patzner R.A., 1998). The inaugural research on artificial breeding was started in 1950 (Linhart et al., 2003). The performed research strived to determine reliable and practical, as well as easily applied artificial breeding technologies, appropriate for artificial incubation of common carp. In order to remove fish egg adheviseness, we see employed such traditional methods as fertilized egg mixing in Woynarovich solution (salt and urea), milk powder and water solution (Schoonbee and Brant, 1982), solution of talc, clay and water (Gela et al. 2003; Mizuno et al., 2004) or tannic acid solution Demska-Zakes et al. 2005; Zarski, et al., 2015), or using alcalase enzyme ( Linhart et al., 2003; Linhart et al., 2004). Or pineapple juices (Paterson and Nwashi, 2014).

The majority of reviewed literature concentrated on removing egg adhesiveness in sturgeon, pikeperch, snapper, african catfish and other fish eggs by using tannic acid (Zakęś Z. and Demska-Zakęś K, 2009; Muchlisin et al., 2014; Siddique et al., 2016; Asraf et al., 2013; Ashraf M. and Bengston D, 2007).

Carp egg adhesiveness can be removed using different methods, but often in fishery practice Woynarovich (1962) method is used. With this method, eggs are washed in urea and salt solution, afterwards - very briefly washed in tannic acid solution. The first part of the adhesiveness removal procedure does not have any effect on embryo development, but the further process might have an effect on development and even mortality of embryos, depending on tannic solution concentration and the duration which the eggs were submerged in the solution (Kujawa et al., 2010).

Until now, in the Fisheries Service under the Ministry of Agriculture of the Republic of Lithuania Šilavotas subdivision under the division of Internal water and Aquaculture, carp egg adhesiveness removal process has been

Copyright (C) 2017 The Authors. Published by Aleksandras Stulginskis University. This is an open-access article distributed under the terms of the Creative Commons Attribution License (CC-BY 4.0), which permits unrestricted use, distribution, and reproduction in any medium, provided the original author and source are credited. 
performed by mixing fertilized eggs in milk-salt-water solution. The goal of this research is to attempt to apply previously never employed techniques of removing the common carp egg adhesiveness and investigate the improvement of the fertilization and hatchability.

\section{METHODOLOGY}

This research was performed in the Fisheries Service under the Ministry of Agriculture of the Republic of Lithuania Šilavotas subdivision under the division of Internal Water and Aquaculture. Due to extremely unfavourable weather conditions, too low air temperature, which directly influences changes in water temperature, carp incubation was performed four times this year: June 6th, 10th, 12th and 15th. Water temperature and dissolved oxygen levels were constantly monitored (image 1). Overall, 187 carp reproductors were utilized in all the incubations. In mid-May, females were separated from males and were held in different ponds until the start of the incubation. On June $10^{\text {th }}, 24$ females and 20 males were selected for incubation. Carp is a fish of portion spawning, thus in order to ensure, that breeding material (eggs and roe) would mature simultaneously, reproductors are injected with a sexual hormone hypophysis. Females were injected two times during a twelve hour interval; males were injected once, at the same time as the females got the second injection. The amount of hypophysis is determined by the weight of the fish - for females: first injection - $0,5 \mathrm{mg}$ for $1 \mathrm{~kg}$ of fish, second injection - $3 \mathrm{mg}$ for $1 \mathrm{~kg}$ of fish; for males - 2,5 mg for $1 \mathrm{~kg}$ of fish (Mengxi Cao et al., 2013, Lawson, et al, 2010). During June 10th's incubation, hipophysis solution was respectively injected on June 9th at 12:30pm and June 10th 12:30am. During the second injection, female sexual openings were sutured.

Before taking out the eggs and roe, fish were anesthetized in 2-phenoxyethanol $0.5 \mathrm{~cm}^{3} / \mathrm{dm}^{3}$ water solution.

This year, for the first time ever, during incubation, tannic acid was used as unsticking material. In order to compare the features of these two technologies, adhesiveness from a part of the eggs (43\%) was removed using milk, salt and water solution, from another part (57\%) - tannic acid and water solution.

Preparation of milk solution. Milk, water and salt solution was based on the following proportions: 1 litre of milk +7 litres of water $+50 \mathrm{~g}$ of $\mathrm{NaCl}$. Adhesiveness is removed from fertilized eggs in bowls by mixing them with geese feathers for no shorter than 60 minutes. During mixing in milk solution, the eggs instantly unstick from one another, begin to gradually swell. During mixing, solution is constantly being poured into the bowl in order to maintain appropriate amount and eggs wouldn't start to adhere to one another again. The volume of mixed material increases three to four times.

Preparation of tannic solution. The tannic acid solution was prepared by mixing 7 grams of tannic acid powder with 5 litres of water. 1 litre of solution is immediately poured into a bowl with fertilized eggs. Adhesiveness is removed from fertilized eggs in bowls by intensively mixing them for 10 minutes. At the beginning of mixing, eggs adhere to one another, hardly unstick, but with constant mixing and pouring additional amount of solution, eggs unstick. With the use of tannin, the eggs swell much less, the overall volume of mixed material, compared to eggs mixed in milk solution, is two-three times lower.

Using both milk and tannic acid solutions, after mixing, eggs are transferred to Weiss jars. In them, eggs are mixed with the help of from below flowing water stream.

During the process of incubation, 3.7 million eggs were fertilized; out of them 1.6 million were rid of adhesiveness by milk solution, 2.1 - by tannic solution. The amount of hatched larvae is one of the most important criteria for evaluating artificial breeding effectiveness in most often in aquaculture grown fish species (carp, pikeperch, snapper). Breeding effectiveness was determined by calculating the percentage of fertilized eggs and hatched larvae.

\section{RESULTS AND DISCUSSION}

The beginning of carp hatchering mostly depends on water temperature. The best temperature for carp hatchering is $19-28^{\circ} \mathrm{C}$. For this reason, water temperature and dissolved oxygen levels were constantly monitored during the hatchering. These water quality parameters were monitored for the whole incubation period from egg maturation until larvae hatching, i.e. from June 6th to 26th, every hour during morning and day, and every $2-3-$ hours during night. The results of the monitoring are presented in Image 1 . The lowest recorded water temperature was $16,6^{\circ} \mathrm{C}$, the highest $-22,7^{\circ} \mathrm{C}$. According to research, conducted by Sapkale et al. (2011) the optimal water temperature for common carp Cyprinus carpio is $26^{\circ} \mathrm{C}$, as in this temperature, the viability of carp embryos reaches $96 \%$. For the fertilization of carp eggs, the time was chosen when the water temperature of the pond increased and at least for several hours kept high. 


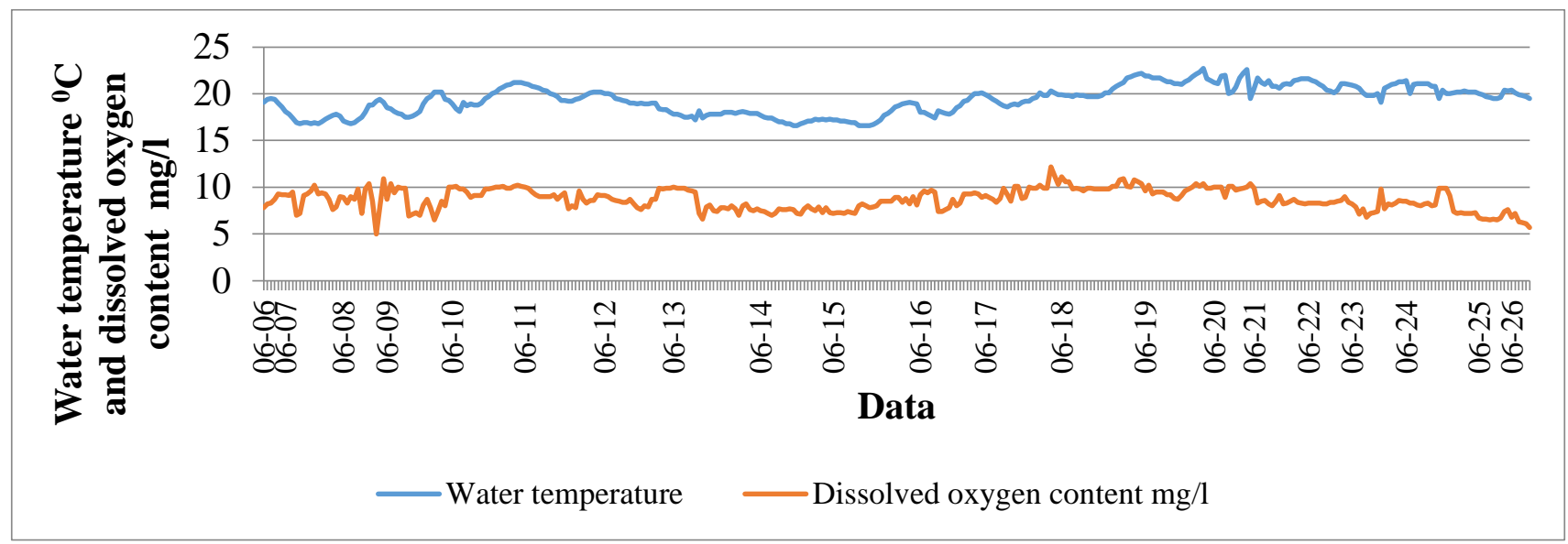

Figure 1. Results of water temperature and dissolved oxygen amount monitoring

Carp egg fertilization procedure must be performed very rapidly, as fish perm remains viable only for a very short time. Fertilized eggs are transferred to Weiss jars. It has been noticed, that eggs, mixed in milk solution, had the tendency to stick to the sides of the jar, thus they need to be mixed occasionally with geese feathers. After 30 mins, the eggs are rinsed enough to lose adhesiveness and give in to the stream of supplied water. Eggs, mixed in tannic acid solution do not stick to the walls, but some of them remain adhering to one another and float in small groups. As mentioned before, eggs with tannic acid swell less, are smaller, assume a darker brownish tint (see figures 2 and 3)

Depending on water temperature, on the 2nd-4th incubation day, saprolegnia pathogens start reproducing rapidly in the bulbs Eggs, affected by saprolegnia lose their vitality and need to be expelled as to not endanger other healthy eggs. In the bulbs, in which the egg gone through adhesiveness elimination procedure with milk solution, eggs, affected by saprolegnia and otherwise dead, easily separate from the healthy ones and start floating at the top with the help of decreased water circulation. Such eggs can be easily disposed of with the help of pipette and a small hose. Simultaneously, eggs, gone through a process of adhesiveness removal with tannic acid solution (especially those who remained adhered to one another), float in the total egg mass and do not start to float at the top. Such eggs are very hard to separate. Undeveloped eggs that are dead and affected by saprolegnia become carriers of this fungal disease and infect a much larger number of eggs.

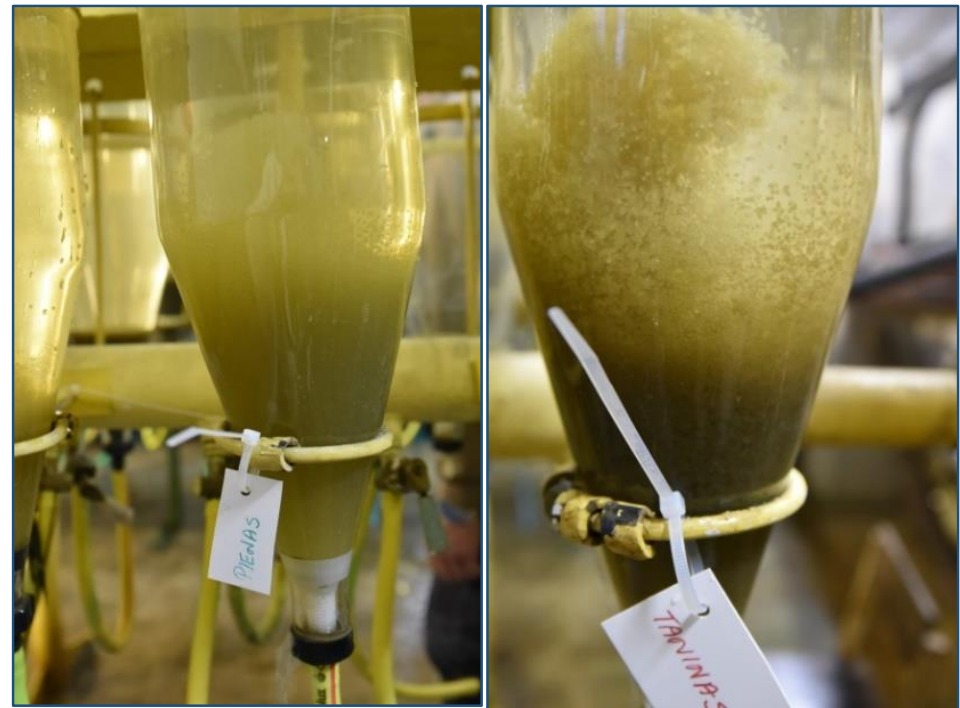

Figure 2. Carp eggs in Weiss jar in milk (left) and tannic acid (right) solutions (image by L. Švirinienè)

During the process of incubation, 3.7 million eggs were fertilized; out of them 1.6 million were rid of adhesiveness by milk solution, 2.1 - by tannic solution. It is plausible that unfavourable environmental conditions influenced the low egg vitality. $750000(47 \%)$ carp larvae hatched from milk solution treated eggs, while $800000(38 \%)$ of larvae hatched from the eggs treated with tannic solution. 


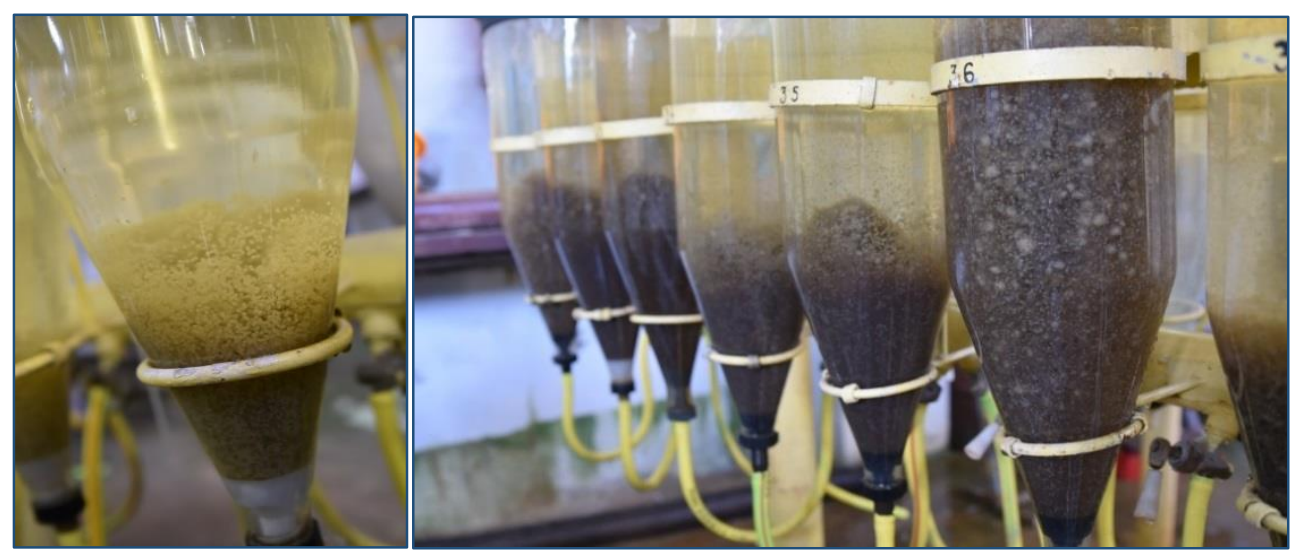

Figure 3. Eggs (white derivatives), affected by saprolegnia in milk (left) and tannic acid (right) solutions (image by L. Švirinienè)

Fertilization percentage is relatively low. We can try to find several reasons for that. One of them - the lack of experience in using tannic acid for removing egg adhesiveness. In artificial fertilization, the effectiveness of incubation and removing egg adhesiveness plays a crucial role for egg and, later, larvae vitality (Demska-Zakes et al. 2005; Siddique et al. 2014; Zarski et al. 2012).. Other authors (Kujawa et al., 2010) state that using tannic acid solution in order to remove egg adhesiveness, best results were achieved by using 0,05\% tannic acid solution, submerging eggs for 30-90 seconds or using $0,1 \%$ solution, submerging eggs for 30 seconds. Using these concentrations, the eggs did not stick to each other and a large percentage of tench larvae hatched. On the other hand, submerging tench eggs for 60 seconds in 0.10 and $0.15 \%$ concentration tannic solutions provoked high embryo mortality during incubation as the solution hardened the egg membrane (capsule). In Šilavotas subdivision, $0,14 \%$ concentration tannic solution was prepared for removing egg adhesiveness, eggs were mixed in the solution for 10 minutes. When embryos reach the end of incubation period, a gland is formed, which secretes hatching ferment. This ferment is extremely important as it reduces the strength of egg's outer membrane and melts it, thus the embryo can shred it. in different instance, the egg membrane would be unsurmountable for almost all fish species. It is possible, that due to use of tannic acid solution, the egg membrane hardened to such a degree that the embryos died as they could not tear the membrane.

Another possible reason for low egg fertilization percentage is saprolegnia disease. Egg adhesiveness does not cause problems during the process of fertilization, but it the adhesiveness is removed improperly and eggs adhere to one another, the dissolved oxygen circulation among eggs decreases and a danger of fungal diseases arises (Siddique et al. 2014). Eggs that were held in the tannic solution were clumped together thus could not float to the surface. On the other hand, eggs with hardened membranes become heavier and cannot float as well, thus aggravating the management of spread of saprolegnia.

Low vitality of carp sperm could be another reason for a lower percentage of fertilized eggs in tannic solution. In Dadras et al. (2017) article it is stated that the speed of carp spermatozoon movement highly depends on water temperature. These authors researched spermatozoon movement speed at water temperatures of $4^{\circ} \mathrm{C}, 14^{\circ} \mathrm{C}$ and $24^{\circ} \mathrm{C}$ and the results showed, that the highest spermatozoon speed was achieved in $24^{\circ} \mathrm{C}$ temperature water. The highest achieved temperature in Šilavotas subdivision during carp incubation was merely $22,7^{\circ} \mathrm{C}$. Water salinity also has huge impact of sperm vitality as salt acts as sperm activator. As Hakim et al. (2008) state, carp spermatozoon was more viable and a higher percentage of larvae survived when the salinity of solution, used for egg adhesiveness, was 5-10\%. In this research it was established, that a higher percentage of larvae hatched when using the milk, water and salt solution used for egg adhesiveness removal than using tannic acid solution.

By analysing academic research on carp egg adhesiveness removal we can state that tannic acid solution can be successfully used in artificial carp fertilization.

\section{CONCLUSIONS}

1. The level of carp breeding effectiveness in Silavotas division during 2017 spring-summer period was determined by environmental conditions, unsuitable for carp breeding (low water temperature).

2. 2.The carp larvae hatching percentage (38\%) using tannic acid solution to remove egg adhesiveness was lower than using the usual milk+salt+water solution (47\%), due to prolonged immersion in tannic acid solution and too low water temperature.

3. Using tannic acid solution to remove egg adhesiveness shortens the duration of carp egg fertilization procedure from one hour to ten minutes or less.

4. The successful use of tannic acid solution for removing egg adhesiveness depends on the concentration of the solution and duration of egg immersion.

\section{REFERENCES}

1. Paterson, A.E., Nwachi, F.O. 2014. Use Of Pineapple Juice In The Elimination Of Egg Stickiness In Mudfish (Heterobranchus bidorsalis). Global Journal of Bio-science and Biotechnology, Vol. 3, Iss. 2, pp. 161-163. 
2. Asraf, A., Zainal, M., Mohd A., Siti-Azizah, N. 2013. Removal of Eggs Adhesiveness of African catfish (Clarias gariepinus) at Different Concentrations of Urea Solution.. Aceh International Journal of Science \& Technology, Vol. 2, Iss. 3, pp. 94-97. https://doi.org/10.13170/AIJST.0203.04

3. Ashraf M., Bengtson D. A. 2007. Effect of Tannic Acid on Feed Intake, Survival and Growth of Striped Bass (Morone saxatilis) larvae. International Journal Of Agriculture \& Biology, Vol. 9, No. 5, pp. 751-754.

4. Dadras H., Sampels,S. Amin G. Dzyuba V., Cosson J., Dzyuba B. Analysis of common carp Cyprinus carpio sperm motility andlipid composition using different in vitro temperatures. 2017. Animal Reproduction Science, Vol. 180, pp. 37-43. https://doi.org/10.1016/j.anireprosci.2017.02.011

5. Demska-Zakes K., Zakes Z., Roszuk J. 2005. The use of tannic acid to remove adhesiveness from pikeperch, Sander lucioperca eggs. Aquaculture research, Vol. 36, pp. 1458-1464. https://doi.org/10.1111/j.1365-2109.2005.01370.x

6. Hakim A. E. El-Gamal and Zeinab A. El-Greisy. 2008. Effect of Removal of Egg Adhesiveness on Hatchability and Effect of Different Levels of Salinity on Survival and Larval Development in Common Carp, Cyprinus Carpio. Journal of Applied Sciences, Vol. 4, Iss. (12), pp. 1935-1945.

7. Gela D., Linhart O., Flasjshans M., Rodina M., 2003. Egg incubation time and hatching success in tench (Tinca tinca L.) related to the procedure of egg stickiness elimination. Journal of Applied Ichthyology, Vol. 19, pp. $132-133$. https://doi.org/10.1046/j.1439-0426.2003.00465.x

8. Kujawa R., Kucharczyk D., Mamc A. 2010.The effect of tannin concentration and egg unsticking time on the hatching success of tench Tinca tinca (L.) larvae. Reviews in Fish Biology and Fisheries, Vol. 20, pp. 339-343. https://doi.org/10.1007/s11160-0099136-z

9. Linhart O., Rodina M., Gela D., Kocour M. \& Rodriguez M. 2003. Improvement of common carp artificial reproduction using enzyme for elimination of egg stickiness. Aquatic Living Resources, Vol. 16, 450-456. https://doi.org/10.1016/S0990$\underline{7440(03) 00083-4}$

10. Linhart O, Rodina M, Gela D, Flajšhans M, Kocour M. 2004.Enzyme treatment for elimination of egg stickiness in tench (Tinca Tinca L.), European catfish (Silurus Glanis L.) and common carp (Cyprinus Carpio L.) Fish Physiology and Biochemistry, Vol. 28, pp. 507-508. https://doi.org/10.1023/B:FISH.0000030643.47857.23

11. Mengxi C., Chen J., Peng W., Wang Y., Lanjie L., Yongming L., Vance L.T, Zuoyan Z, Hu Wei. 2014. Effects of growth hormone overexpression on reproduction in the common carp Cyprinus carpio L. General and Comparative Endocrinology, Vol. 195, pp. $47-57$.

12. Mizuno S., Sasaki Y., Omoto N. Imada K. 2004. Elimination of adhesiveness in the eggs of shishamo smelt Spirinchus lanceolatus using kaolin treatment to achieve high hatching rate in an environment with a high iron concentration. Aquaculture, Vol. 242, Iss. 1-4, pp.713-726. https://doi.org/10.1016/j.aquaculture.2004.09.019

13. Muchlisin, Z. A., Siti, M., Fadli A.A.N., Afrizal H., Siti-Azizah M.N. 2014. A preliminary study to evaluate the effects of powder milk solution on the eggs adhesiveness and fertilization rates of African catfish, Clarias gariepinus. International Journal of the Bioflux Society..

14. , Riehl R., Patzner R.A. 1998. Minireview: The modes of egg attachment in teleost fishes. Italian Journal of Zoology, Vol. 65, Iss. S1, pp. 415-420, https://doi.org/10.1080/11250009809386857

15. Sapkale P.H., Singh R.K. \& Desai A.S. 2011. Optimal water temperature and pH for development of eggs and growth of spawn of common carp (Cyprinus carpio). Journal of Applied Animal Research, Vol. 39, Iss. 4, pp. 339-345, https://doi.org/10.1080/09712119.2011.620269

16. Schoonbee, H.J., Brandt, F.De.W. 1982. Observations on Some Techniques Employed for the Removal of Egg Adhesiveness of the Common Carp, Cyprinus carpio, During Induced Spawning. http://www.wrc.org.za/Knowledge\%20Hub\%20Documents/Water\%20SA\%20Journals/Manuscripts/1982/WaterSA_1982_\%208 _0241b.PDF

17. Siddique, M. A. M., Psenicka, M., Cosson, J., Dzyuba, B., Rodina, M., Golpour, A., Linhart, O.2014. Egg stickiness in artificial reproduction of sturgeon: an overview. Reviews in Aquaculture, Vol. 8, pp. 18-29. https://doi.org/10.1111/raq.12070

18. Siddique, MAM, Linhart, O, Krejszeff, S, Żarski, D, Król, J, Butts, I.A. E. 2016. Effects of pre-incubation of eggs and activation medium on the percentage of eyed embryos in Ide (Leuciscus idus), an externally. Theriogenology, Vol. 85, Iss. 5, pp. 849-855 https://doi.org/10.1016/j.theriogenology.2015.10.032

19. Zakẹś Z., Demska-Zakẹś K. 2009. Controlled reproduction of pikeperch Sander lucioperca (L.): a review. Archives of Polish Fisheries, Vol. 17, pp. 153-170.

20. Zarski, D., Kucharczyk D., Targonska K., Palinska K., Kupren K.,, Fontaine, P., Kestemont, P. 2012: A new classification of prieovulatory oocyte maturation stages in pikeperch, Sander lucioperca (L), and its application during artificial reproduction. Aquaculture research, Vol. 43, pp. 713-721. https://doi.org/10.1111/j.1365-2109.2011.02879.x

21. Zarski, D., Krejszeff, S., Kucharczyk, D Palinska-Zarska, K., Targonska, K., Kupren, Fontaine, P., Kestemont, P. 2015: The application of tannic acid to the elimination of egg stickiness at varied moments of the egg swelling process in pikeperch, Sander lucioperca (L.). Aquaculture Research, Vol. 46, Iss. 2 , pp. 324-334. https://doi.org/10.1111/are.12183 